\title{
Brief history of THz and IR technologies
}

\author{
F.F. Sizov \\ V. Lashkaryov Institute of Semiconductor Physics, NAS of Ukraine, \\ 41, prospect Nauky, 03680 Kyiv, Ukraine, e-mail: sizov@isp.kiev.ua
}

\begin{abstract}
Brief history of terahertz (THz) and infrared (IR) science and technology, for learning lessons by historical evolution is presented and discussed identifying important (from Author's point of view) steps for their development. THz still is the not well-known region of electro-magnetic science, even it has been lightened by starting of scientific and technological knowledge, since the end of $19^{\text {th }}$ century. As concerning history of IR science and technology, it took many years since 1800 (W. Hershel) to reach the level of use that is recognized today. The link between IR and thermal science and applications was so strong that IR was for a long time synonymous of thermography. THz science and technology are showing a rapid growth. IR and, especially $\mathrm{THz}$ technologies, now have become one of the major fields of applied research. Nowadays, they become widely spread in their use in astrophysics, security, biomedicine, detection of hidden objects, food and art inspection, etc. The increasing requirements for fast transmission of large amounts of data will lead to the extension of operation frequencies in communications toward the $\mathrm{THz}$ frequency range. IR and $\mathrm{THz}$ medical imaging can provide guidance for surgeons in delimiting the tumor margins, help clinicians visualize diseased area, etc. A few decades ago, IR technologies were mainly the domain of military ones. In recent two decades, due to widespread of lowcost thermal uncooled arrays there were realized many IR technology advances in civil and military applications. A large amount of $\mathrm{THz}$ technologies mass-market applications can't be highlighted, as these technologies do not meet yet the user requirements, especially in easiness of use and costs. Still, many of $\mathrm{THz}$ applications that we have now are emerging and showing their applicability in some implementations, where other methods can't give any comprehensive information, e.g., in dry food inspection for dielectric inclusions, skin tumour margins control, $\mathrm{THz}$ astronomy, package and envelope inspection, etc. The brief lessons given by historical highlights in $\mathrm{THz}$ and IR science and applications can be important for the future developments in these directions as history frequently opens routes for new thinking. In this brief review, the missed important steps can happen. Author apologizes for these possible faults.
\end{abstract}

Keywords: THz and IR technologies, devices and instrumentation, history.

doi: https://doi.org/10.15407/spqeo22.01.67

PACS 87.50.U-, 87.64.km, 87.80.Dj, 87.85.Ox

Manuscript received 12.01.19; revised version received 17.02.19; accepted for publication 27.03.19; published online 30.03.19.

\section{Introduction}

The infrared (IR) and, especially terahertz (THz) technologies, now have become one of the major fields of applied research driven, to a great degree, by potential imaging and spectroscopy applications in astronomy, biomedicine, security screening applications for detecting hidden objects, dry food inspection, etc. The increasing demand for fast transmission of large amounts of data will lead to the extension of operation frequencies in communications, toward the $\mathrm{THz}$ frequency range. The IR and $\mathrm{THz}$ medical imaging technologies can provide guidance for surgeons in delimiting the margins of tumors, help clinicians visualize diseased area, etc.

Scientific and particularly application activity in the $\mathrm{THz}$ and IR technologies have significantly increased in the recent three decades, and it is to be expected that the trends, especially in $\mathrm{THz}$ science and technology, will be continued and extended.

In these developments, there is a priority to the developing of imaging and spectroscopic systems. The $\mathrm{THz}$ technologies, due to their non-ionizing influence and detection capability of hidden objects in clothing as well as in packaging containers and luggage, when 
coupled to the spectroscopic detection of explosives, chemical and biological agents, are the promising ones. As concerning the IR technologies, it should be pointed out their growing usage in the civilian sphere. There is the noticeable price decrease in these expensive technologies due to development of new large uncooled matrix arrays and cameras, which, to a great extent, revolutionized the civilian and military applications of imaging.

Here, a brief introduction to the history of $\mathrm{THz}$ and IR technologies for learning by historical lessons is presented. These brief lessons learnt by historical highlights in $\mathrm{THz}$ and IR science can be expected as important for the future developments in these directions, since the history frequently opens routes for new thinking. In this brief review, the missed important steps can happen. The author apologizes for these possible faults.

\section{Brief history of $\mathrm{THz}$ technologies}

The terahertz $(\mathrm{THz})$ region of electromagnetic spectrum some time ago was often described as the final unexplored area of the electromagnetic wave spectrum. Until about three decades ago, the $\mathrm{THz}$ range of the spectrum was complicated of its potential for application, largely because of the difficulty in providing suitable sources and detectors. However, during a couple of recent decades the $\mathrm{THz}$ science and technology have been showing a rapid growth. Now these technologies are among the widely investigated research topics and applications (see, e.g., [1, 2]).

Shown in Fig. 1 are electromagnetic spectra from ultraviolet (UV) to radio wavelength region. Now it is commonly accepted that the $\mathrm{THz}$ region is within radiation frequencies from $v=0.1 \mathrm{THz}$ to $10 \mathrm{THz}$. The IR region is settled between 0.75 and $30 \mu \mathrm{m}$ $(v=400 \ldots 10 \mathrm{THz})$.

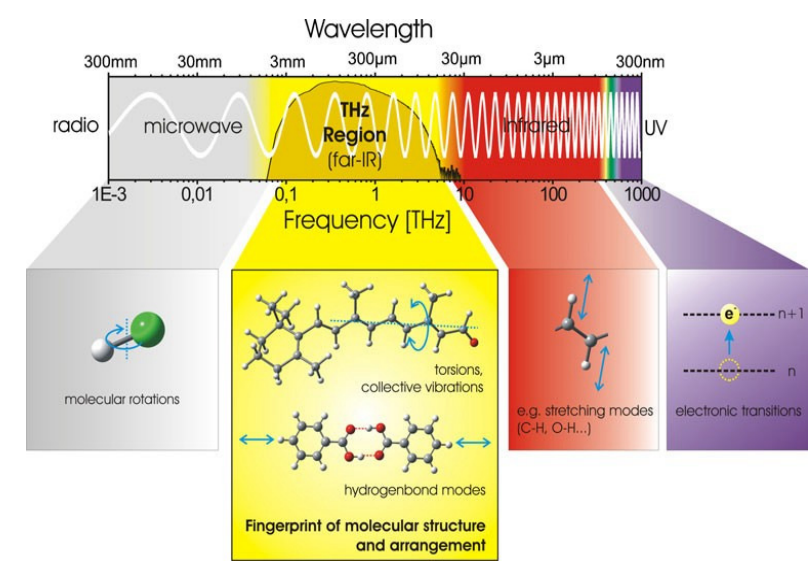

Fig. 1. The electromagnetic spectrum with corresponding molecular excitations [3]. The frequency-dependent amplitude of a typical terahertz pulse frequency range $(0.1 \ldots 5 \mathrm{THz})$, which is frequently used for $\mathrm{THz}$ imaging and spectroscopy, is indicated in the spectrum by the dark-yellow area.
The research in this spectral range seems to have its origin from the electromagnetic waves (radio waves) discovery (H. Hertz, 1885-1989, "At this location, Heinrich Hertz discovered the electromagnetic waves in the years 1885-1889", from the Memorial for H. Hertz at the University of Karlsruhe). The experiments conducted by Hertz dealt with generating and receiving the EM waves with the wavelength of $66 \mathrm{~cm} \mathrm{[4].}$

H. Hertz had no idea that this transmission of electromagnetic waves can be used to information communication [5]. It was Guglielmo M. Marconi, who thougt he could use Hertzian waves to send signals [6]. Marconi used spark transmitter as no amplitude modulation technique or active non-linear devices were known that time.

G. Marconi's achievement was public demonstration of sending wireless signal remotely on Salisbury Plain, U.K., that was not until May 1897. Perhaps, it is worth noting that J. Bose had given a public demonstration of wireless transmission over a mile in 1895 to remotely ring a bell and to explode gunpowder [4].

Despite the thoughts that it is not feasible to transmit an information through long distance as EM waves behave like light and thus couldn't bend to the Earth's curvature, in 1901, G. Marconi first demonstrated the trans-Atlantic radio waves transmission of around 2000 miles between Poldhu, UK and Newfoundland, St. Johns, Canada (likely it was at $820 \mathrm{kHz}$ ). To detect the first trans-Atlantic wireless signal (three dots representing the letter "S") G. Marconi used a $150 \mathrm{~m}$ long wire antenna put on a kite and "coherer" to convert an alternating signal into the direct current to measure by using a telephone receiver to hear this signal. J.C. Bose at his lecture at Royal Society in 1899 proposed alike coherer [5, 7].

In Germany, Ch. Hülsmeyer was the first to use radio waves to detect "the presence of distant metallic objects" (1904), he demonstrated the feasibility of detecting a ship in dense fog, but not its distance [8].

The history of $\mathrm{THz}$ technologies in different periods is presented e.g., in a number of papers and books [8-13].

In 1897, H. Rubens and E.F. Nichols first explicitly noted the existence of a gap in the electromagnetic spectrum, between the optical and electronic sources of radiation [13].

Although a lot of works in the $\mathrm{THz}$ spectral range has already been done under the older terms "far infrared" (see, e.g., $[14,15])$ or sub-mm waves (see, e.g., $[16,17])$, the term "terahertz" stands for a novel technique offering many potential applications applying the $\mathrm{THz}$ technologies to industry, medicine, detection of drugs and explosives, telecommunications, etc. The term "terahertz" also represents a new generation of systems.

Historically, $\mathrm{THz}$ technologies were mainly used within the astronomy community for studying the background of cosmic far-infrared radiation. They were also used by the laser-fusion community for the diagnostics of plasmas. The earliest investigations and papers on measuring the energy content of the blackbody radiation in the far infrared region published up to 1920 s 
were made by H. Rubens [18] in the far IR (FIR) spectral region. H. Rubens' experiments were mainly concentrated on the extension of the IR spectral region into the FIR and absorption of water vapor in this spectral region (see [19]).

Now, as it is proved, $\mathrm{THz}$ technologies are important for imaging and spectroscopy in spite of highly absorbing environmental Earth conditions. The clothing, plastic packaging equipment and microcircuit bodies are transparent in the $\mathrm{THz}$ spectral range $(v \leq 1 \mathrm{THz})$. It gives the opportunity not only to reveal ceramic weapon and many types of explosives on the human body as they are highly reflective substances due to difference in dielectric permittivity or high water content, but also different types of diseases (as a rule in the reflection mode) - biomedical applications. It makes usage of $\mathrm{THz}$ technologies to be challenging in various types of applications.

For $\mathrm{THz}$ science and technology, important was the work by J.C. Bose at the Presidency College, Calcutta, with which he started in the 1894 on wireless sub-THz experiments with new sensors, spark generators, polarizers and sources. The shortest wavelength used in Bose's experiments was about $5 \mathrm{~mm}$. He invented contact detectors involving metals and semiconductors [20].

Important was an invention of galena crystal detector [21]. In this patent J.C. Bose claimed "A coherer or detector of electrical disturbances, Hertzian waves, light-waves or other radiations, comprising contacting pieces of sensitive substance having a characteristic curve (giving the relation between an increasing impressed electromotive force and the resultant current passing through the sensitive substance), which is not straight but is either convex or concave". This was a point-contact semiconductor rectifier, involving a contact device with galena (lead sulfide), the first patent for a semiconductor device in the world (see, e.g., [8, 13]). Later this device was used as a receiver for demodulation continuous wave radio signals. This was the first semiconductor diode detector, although the terms "diode" and "semicon-ductor" were not known yet. In 1954, G. Pearson and W. Brattain [22] gave priority to Bose for the use of a semiconducting crystal as a detector of radio waves.

After the World War I, E.F. Nichols performed a series of experiments with short electric waves by developing improved radiometer receivers and Hertzian oscillators. E.F. Nichols and J.D. Tear (1923) succeeded in obtaining wavelengths down to $1.8 \mathrm{~mm}$ by using the interferometric method [13]. In 1923, A. GlagolevaArkadieva [23] showed the possibility to get a source (using Al sawdust in thick oil as Hertzian oscillators) operating within the wavelengths from $5 \mathrm{~cm}$ down to $82 \mu \mathrm{m}(v \approx 3.66 \mathrm{THz})$. These works in producing such electromagnetic wavelengths filled the gap between spectra of the IR and radio wavelengths.

From the middle of 1920 s up to 1950 s-1960s, there was a relatively steady flow of papers, when a rapid expansion of papers began growing up (see, e.g., $[1,10])$.
Radar (radio-detection and ranging) was invented in 1930 s, whereas a working radar system for detection of ships was actually demonstrated in Germany in 1904 (C. Huelsmeyer) [8] not allowing to directly measure the distance to a target but detecting only the presence of distant objects. This work was not materialized in applications, since there was no real need for radar at that time. It was not until the maturing of the airplane in 1930 that a real need for radar to be developed. By 1939, England had established a chain of radar stations along its south and east coasts to detect aggressors in the air or on the sea. Except UK, several nations were independently developing the systems of this type (Germany, the United States, the former USSR, Japan, the Netherlands, France, and Italy). The designing and testing of gun-aiming radar was performed in Ukraine (Kharkiv) in 1935-1940 [24]. The role in the development of Ukrainian microwave, antenna, radar and remote sensing was indicated in 2015 by awarding the status of IEEE Milestone [25]. The development of radar systems led to new magnetron and klystron sources, and these were employed for microwave spectroscopy experiments.

Since then, it followed a continual progress and development in technology for both sources and detectors. Shortly after the World War II, the Golay cell, which is still in use today, was proposed (M.J.E. Golay, 1946-1947) (see part "Brief history of IR technologies").

The genesis of microwave, and ultimately $\mathrm{THz}$ spectroscopy, was the war time development of microwave radar. By 1948, the field was mature enough [26]. The technology advanced rapidly and by 1954 the submillimeter threshold at $300 \mathrm{GHz}$ had been passed [27]. This drive toward ever higher frequencies was aided by the rapidly increasing absorption strengths of the spectra of many of the most important small fundamental molecules (e.g., carbon, chlorine, nitrogen, oxygen, etc.).

Prediction of the existence of "relict radiation" (the cosmic microwave background (CMB)) remaining from the "Big Bang" was made in 1948 by R. Alpher and G. Gamow [28] developing G. Lemaître's Big Bang theory (late 1920s-1930s). R. Alpher and R. Herman estimated what temperature of the cosmic microwave background ought to be. They obtained $T \approx 5 \mathrm{~K}$ (the precise measured temperature of microwaves is $T=2.725$ degrees Kelvin [29] that corresponds to $\lambda_{\max } \approx 1.064 \mathrm{~mm}\left(v_{\max } \approx 282 \mathrm{GHz}\right)$ of the blackbody radiation. Measurements of the $\mathrm{CMB}$ at various frequencies from different platforms showed it to have the spectrum of thermal blackbody spectrum, as predicted by the Big Bang model [30].

The first direct observation of CMB was made in 1964 by A. Penzias and R. Wilson [31], who were trying to measure background microwave interference to enable noise-free communication within this spectral band for AT\&T. They were conducting experiments with the sensitive Holmdel Horn Antenna, originally used to detect radio waves that were bounced off Echo balloon satellites, and later the Telstar, the first active communications satellite. They determined that the 
buzzing noise was coming from all parts of the sky at all times of day and night from outside of our galaxy.

During 1950s, foundations were laid from grating spectroscopy, in which for high resolution narrow slits were required, to Fourie-transform spectroscopy (FTS) having large apertures, though it was progressing relatively slow, which was mainly caused by limitations of computer technique. Of the papers published in 1950s, about $80 \%$ concerned applications were related with the study of semiconductor optical properties (e.g., cyclotron resonance), absorption spectra of gases, diagnostics of high-temperature plasmas, etc. [10].

In the early 1950s, there appeared the first carcinotrons or backward wave oscillators (BWO). This high power ( $\mathrm{mW}$ range at $1 \mathrm{THz}$ ) source was demonstrated for the first time in 1952 offering a limited electronic tunability $(\sim 10 \%)$. It was French-made BWO tube [32] that was called carcinotrons - derived from the Greek word for Cancer (crab). The late 1950s are characterized by starting the development of high-power gyrotrons (the USA, Australia, the former USSR) [10]. The gyrotrons are members of a specific family of devices in the class of vacuum electronic sources of coherent microwave radiation.

Important for using in radar and alarm systems as $\mathrm{GHz}$ radiation sources are IMPATT diodes. In 1958, W. Read [33] proposed operation principles of this device. $\mathrm{W}$. Read showed that an avalanche diode, when impact ionization is used to inject electrons, a significant transit time delay might exhibit a negative resistance characteristic that is required for the beginning of oscillations. Devised in 1959 were avalanche transit-time diodes (IMPATT diodes) in Ge on the base of coherent oscillations generation at avalanche breakdown microwave frequency diffusion diodes (for Refs. see [34]). Later, the devices (oscillators) based on the phenomenon of microwave frequencies generation were realized in $\mathrm{Si}$ and $\mathrm{GaAs}$ diodes $[35,36]$. The IMPATT diodes have received much attention in recent years as cost-effective and low-sized $\mathrm{THz}$ sources. Their device performance on the base of $\mathrm{Si}$, GaAs, InP has been improved from year to year. The Si IMPATT diodes have more reliable and mature technology.

The experiments in the late 1950s and early 1960s provided a considerable opportunity for $\mathrm{THz}$ science: the emission of $\mathrm{THz}$ radiation from heated plasma delivered temperature and density information; the Golay cell detection and diffraction grating dispersion (G.N. Harding, et al., 1961) were successfully used in probe plasma diagnostics within the $100 \ldots 1500 \mu \mathrm{m}$ band. At that time, BWO sources operational frequency range was subsequently extended to $1 \mathrm{THz}$ and above [13].

The 1960s can be marked by the great progress in detector and source development. Golay cells were widely replaced by pyroelectric detectors. New detectors, though deeply cooled ( $n$-InSb hot electron bolometer, Ge bolometer, Ge:Ga extrinsic photoconductor, detectors based on the Josephson effect) were developed. The important discovery of this decade was the water vapor laser (1964) followed by several other gas lasers, which provided radiation of several continuous wave lines a little bit smaller than the radiation frequency of $1 \mathrm{THz}[10]$.

In the early 1960s, the Gunn effect [37] was found. Gunn diodes are used in Gunn oscillators. These sources are widely used today in the frequency range $v<\sim 0.3 \mathrm{THz}$ for radio communications, military and commercial radar sources.

In the 1960s, there were developed the electrical discharge-pumped $\mathrm{THz}$ sources [38]. They observed strong submillimeter wave emission from low pressure water vapor, using the spectrometer. The optically pumped $\mathrm{THz}$ gas lasers [39] were considered. At the same time, high resolution $\mathrm{THz}$ Fourier transform spectroscopy was developed [40].

Started in the late 1960 s were the studies of the influence of $\mathrm{THz}$ and mm-wave radiation on biological systems. Researchers [41] looked at effects on E. coli. They surveyed growth of the bacteria after $0.136 \mathrm{THz}$ irradiation with estimated power $7 \mu \mathrm{W}$ for 4 hours. Growth inhibition was observed after 2 hours when cells were irradiated in the lag phase and after $1.5 \mathrm{hr}$ when cells were irradiated in the log phase. Later, another group tried to reproduce this experiment [42]. The same object (E. coli) was irradiated with $0.136 \mathrm{THz}$ radiation for $4 \mathrm{hr}$. In contrast to the former investigations, they did not find any evidence for growth inhibition.

In 1960-1970s, an appreciable flow of papers concerning the $\mathrm{THz}$ and microwave spectral regions was registered [1]. These years were important for astronomy at $\mathrm{THz} / \mathrm{sub}-\mathrm{THz}$ frequencies, due to the progress in receivers and high-altitude outboard platform observatories.

The semiconductors band structure conception and impurity properties of semiconductors were widely explored at that time using a BWO, interferometer and molecular-gas laser sources (J.M. Chamberlain et al., 1969, 1972). Remarkable instrumental progress by D.H. Martin (1967) was augmented by the developments in computing techniques, which enabled the full advantages of Fourier transform spectroscopy to be realized [13].

At the end of 1960s, the time domain spectroscopy (TDS) was realized [43]. In this paper, a new method for obtaining the complex permittivity and permeability of linear materials over a broad range of microwave frequencies was described by obtaining the reflected and transmitted transient responses of the component to an incident subnanosecond risetime pulse and then performing discrete Fourier transforms.

There can be noted the progress in new detector technologies for astronomy based on use of uncooled and cooled fast Schottky barrier diodes (SBDs) for both direct detection and mixers applicable at sub- $\mathrm{THz}$ and mm-wave spectral regions* (for Refs. see, e.g., [45]).

* The Schottky barrier diode is named after German physicist Walter H. Schottky, who analyzed the metal-vacuum barrier (Schottky-Nordheim) and later the metal-semiconductor rectifier junction, e.g., [44]. A point contact metalsemiconductor rectifier was first patented by J.C. Bose in 1904 (see above). 
Other detectors important, e.g., in astronomy for heterodyne systems were deeply cooled superconductorinsulator-superconductor (SIS) mixers [46] although the physics of these devices was developed almost two decades earlier.

Important for applications $\mathrm{THz}$ sources can be realized with optical-to-THz conversion by using nonlinear materials as interaction media as well as with photoconductors and photodiodes. In the late 1960s early 1970s, tunable sub-THz radiation obtained by the mixing procedure in nonlinear crystals was used [47, 48].

In 1971, the operation principle of quantum cascade lasers (QCLs) was proposed [49] and first demonstration of QCL was realized at Bell Labs in 1994 [50]. QCLs now are frequently used as solid-state $\mathrm{THz}$ narrow-band sources in the frequency range $v>1 \mathrm{THz}$.

$\mathrm{THz}$ imaging applications in other than astronomical applications started in the middle of $1970 \mathrm{~s}$ (see, e.g., [51]). In this paper, the THz imaging system was based on an HCN laser (operation wavelength $\lambda=$ $337 \mu \mathrm{m}(v=0.89 \mathrm{THz}))$.

In this decade, it was known that an ultra-short optical pulse colliding a photoconductor can generate $\mathrm{THz}$ pulses. The highest frequency of the $\mathrm{THz}$ pulses depends on the optical pulse width and also on the electron mobility in the photoconductor. In the mid1970s, technology of generating optical pulses from a mode-locked Nd:glass laser and high-resistivity Si [52] was used for switching with the photoconductive (PC) structure. This PC switch is often called as Auston switch. The availability of short optical pulses and the development of PC ultrafast semiconductor technology promoted $\mathrm{THz}$ optoelectronics. In 1983, D. Auston and P. Smith [53] using the sampling technique showed coherent detection of a short burst of $\mathrm{THz}$ radiation.

Ge extrinsic photoconductive (though noisy in spite of cooling to liquid He temperatures) detectors were used up to the wavelength $220 \mu \mathrm{m}$ (stressed Ge:Ga photoconductor) [54].

In spite of the fact that $\mathrm{THz}$ radiation has been known for a long time, the technical applications in biomedicine still have not been developed through a lack of suitable sources and detectors [12]. During the recent two to three decades, these problems to a certain degree have been solved.

In the late 1970s, there performed were investigations [55] of hemoglobin and alcohol dehydrogenase that were irradiated. The functional effects were investigated. The authors studied isolated biological systems including enzymes, antibodies, biomolecules, and artificial liposomes. There was applied a sweeping irradiation between 0.075 and $0.115 \mathrm{THz}$. There was not explicitly specified the exposure time, but it can be calculated to be around three hours [56]. Alcohol dehydrogenase activity was measured after irradiation power densities $W \approx 10 . .50 \mathrm{~mW} / \mathrm{cm}^{2}$. No changes of more than $0.1 \%$ were seen. For hemoglobin, oxygen-binding capacity was measured after irradiation with $3 \ldots 13 \mathrm{~mW} / \mathrm{cm}^{2}$, and here no changes of more than $0.4 \%$ were observed. The experimental investigations looked at all biological levels from isolated biomolecules to animals, but up to 2012, no investigation of effects on the human organism was available. The history of $\mathrm{THz}$ radiation influence on biological systems up to $2010 \mathrm{~s}$ is reviewed in [56].

The development in computer technologies (1980s) had made Fourier-transform systems (FTS) to be the choice for spectroscopy through the IR and $\mathrm{THz}$ ranges [9].

In the 1980s, the common today methods of $\mathrm{THz}$ radiation generation with the $\mathrm{PC}$ antenna (PCA) and optical rectification (OR) were considered [57-59].

In [60], it was shown that PCA used as an emitter and a detector have frequency spectra that extend from $v \sim 100 \mathrm{GHz}$ to over $1 \mathrm{THz}$. These are important for $\mathrm{THz}$ time-delay spectroscopy (TDS) and imaging. The advent of mode-locked Ti:sapphire femtosecond lasers [61] in the early 1990s greatly expanded the field of terahertz applications in spectroscopy and imaging. Today a lot of researches in $\mathrm{THz}$ spectroscopy and imaging is carried out using these time-domain spectrometers [10]. In 2000s, THz imaging was applied for non-destructive quality check of hidden damages in foams after the accident with Space Shuttle Columbia in 2003.

Generation and coherent detection of subpicosecond electronic transients conditioned by D. Auston and M. Nuss [62] and by C. Fattinger and D. Grischkowsky [59] were performed.

First lasing in an electrostatic accelerator free electron laser (FEL) emitting in the $\mathrm{THz}$ spectral range was demonstrated at the University of California Santa Barbara (UCSB) [63]. It covered the spectral range from 0.3 up to $0.77 \mathrm{THz}$ with $10 \mathrm{~kW}$ of peak power. This kind of sources is space-consumption having room-building size.

At the end of 1980s, the NbN superconducting hot electron bolometers HEBs were proposed [64] as $\mathrm{THz}$ mixers with the time constant of about $40 \mathrm{ps,} \mathrm{which}$ allowed to realize the bandwidth of several $\mathrm{GHz}$ with an output of $\sim 1 \mu \mathrm{W}$ local oscillator power (LOP) compared to $\sim 1 \mathrm{~mW}$ LOP for SBDs (for Refs. see, e.g., [65]). This superconductor film (NbN) HEB is able to work as thermal detector in a wide spectral range in the IR and $\mathrm{THz}$ domain, but the significant advantage is that it is also able to work as mixer with a wide bandwidth (several GHz). HEBs have been known for quite a while, since the first work on the InSb low-temperature hotelectron heterodyne detector [66, 67]. But this detector can be used in heterodyne systems only, where the bandwidth lies in the $\mathrm{MHz}$ range, because of long recombination times.

In 1993, the PC antenna fabricated on the highspeed low-temperature (LT) grown GaAs used as photomixers to generate $\mathrm{CW} \mathrm{THz}$ radiation [68] was used. The development of this procedure served as a basis for THZ spectroscopy and imaging.

Since the first demonstration of $\mathrm{THz}$ wave timedomain spectroscopy (TDS) in 1980s, there has been a series of significant advances, since more intense $\mathrm{THz}$ sources and higher sensitivity of detectors provide new 
opportunities for understanding the basic science in the $\mathrm{THz}$ frequency range. As developments move forward, $\mathrm{THz}$ science will not only have an impact on material characterization and identification but also have potential applications in the fields of communications, imaging, medical diagnostics, health monitoring, environmental control, chemical and biological sensing, as well as security and quality-control applications. Twenty-first century researches in the $\mathrm{THz}$ field are one of the most promising areas of study for transformational advances in imaging and other interdisciplinary fields (see, e.g., [69]).

In the late 1990s, novel near-field probes were developed, and various applications were demonstrated (see, e.g., [70]).

In 1996, M. Dyakonov and M. Shur [71] considered the $\mathrm{THz}$ response of two-dimensional electron gas in the field-effect transistor channel. Following the considerations of sub-THz/THz trends, detection was demonstrated in III-V HEMTs [72], and more recently, in graphene [73]. As compared to many other uncooled detectors, these devices (e.g., Si-MOSFET and III-V HEMT) can be manufactured at foundry level, since their technology readiness is high.

Recently, acceptable for many $\mathrm{THz}$ and IR applications performances have been obtained with uncooled microbolometer technology. Relatively low cost, high pixel number arrays are now demonstrated. The most reliable and good performances have been obtained both in IR and $\mathrm{THz}$ with good dynamic range by using $\mathrm{VO}_{\mathrm{x}}$ and $\alpha$-Si thin-film materials with thermally isolated microbridges [74].

In the early 2000s, the demonstrations of $\mathrm{THz}$ $(0.1 \ldots 10 \mathrm{THz})$ wireless communications were conducted using both pulsed and continuous waves, which were generated from photoconductors and photodiodes excited by pulse lasers and intensity-modulated lasers (for Refs. see [75]). A little bit later the wireless link employing the $120-\mathrm{GHz}$ band was the first commercial $\mathrm{THz}$ communication system with the allocated bandwidth close to $18 \mathrm{GHz}$, which offers $10 . .20 \mathrm{Gbit} / \mathrm{s}$ modulation for transmission distance of over $5 \mathrm{~km}$ was demonstrated. In the field of $\mathrm{THz}$ communications technique, important progress is the development of active silicon photonics integrated technologies [76, 77].

\section{Brief history of IR technologies}

The story of infrared radiation technologies took many years to reach the level of use that is recognized today. The foundation of the IR detectors mainly in the 19601970 s lead to the growth of thermovision and groundbased IR astronomy in the atmosphere transparency windows, and a little bit later to the observations from the low- and high-altitude observatories to diminish or exclude the water vapor absorption.

The people guess that imaging in the IR range is a technology for getting an additional information from objects that are invisible (e.g., under night conditions) for human eye, which is only sensitive within the spectral range approximately from 0.4 to $0.75 \mu \mathrm{m}$. First humans relied on radiation from the Sun.
The first recorded account of an infrared experiment appears to be that by Jean Batista Della Porta from Naples in his book "Magiae Naturalis", published in 1589 [12]. He found that heat could be sensed when locating a candle in front of a silver plate. When the plate was removed, the sensing of heat from the candle flame was reduced.

In a description of experiments made in 1667, of reflected cold by the Academia del Cimento, it was shown that the mass of ice placed in a vessel, radiate. The registered radiation was concentrated by a concave mirror on a long vertical thermometer and ice made a sensible repercussion of cold upon a thermometer [78].

It was found [78] the note by Petrus van Musschenbroek (1692-1761), probably relating to an experiment made by himself (1755), that the heat from a charcoal fire placed out of an evacuated vessel. However, it passes easily through this vessel, and raises the meter data of a thermometer that was placed at the center of this vessel.

Temperature is a long established indicator of heat. As soon as the thermometer was invented, S. Sanctorius used it in 1612 to measure the heat from the Sun. Using the thermometer, one can maintain the thermal balance of a body to control health conditions, temperature rising or falling enables to conclude of human or animal body disfunction. C. Huygens, O. Roemer, D. Fahrenheit, and later R.A.F. de Reaumur proposed the need for a calibrated scale of thermometers in the late seventeenth and early eighteenth century. A. Celsius proposed a centigrade scale based on ice and boiling water. However, he suggested that boiling water should be zero and melting ice 100 on his scale. It was C. Linnaeus in 1750 who proposed the reversal of this scale, as it is known today. The clinical thermometer, which is used universally in medicine for about 150 years was proposed by $\mathrm{C}$. Wunderlich in 1868 . In the $1960 \mathrm{~s}$, there were proposed liquid crystal sensors for temperature measurements $[79,80]$.

Still, the IR technologies obviously started with amateur astronomer William Herschel's experiments with a thermometer in 1800 . He placed a prism in the path of a sun beam, set thermometers after a prism in various regions of the rainbow and showed that different colors registered different temperatures. By shifting a thermometer further after the red part, he observed some warming. He has concluded it could only be caused by a form of light that is invisible for the human eye. In 1840, John Herschel made a simple image by evaporation of a carbon and alcohol mixture by using focused sunlight. He named the image a "thermogram" $[79,80]$.

Remote sensing of IR radiation became of practical meaning at the end of 1930 s - early1940s. It has continued to develop steadily from the middle of 1950 s. Since that time, the radiometric determination of human body temperature became an important tool, both for medical diagnostics and monitoring treatment. Human heat is associated with many conditions such as inflammation and infection and these conditions may be detected/identified by the IR thermography. It is a non- 


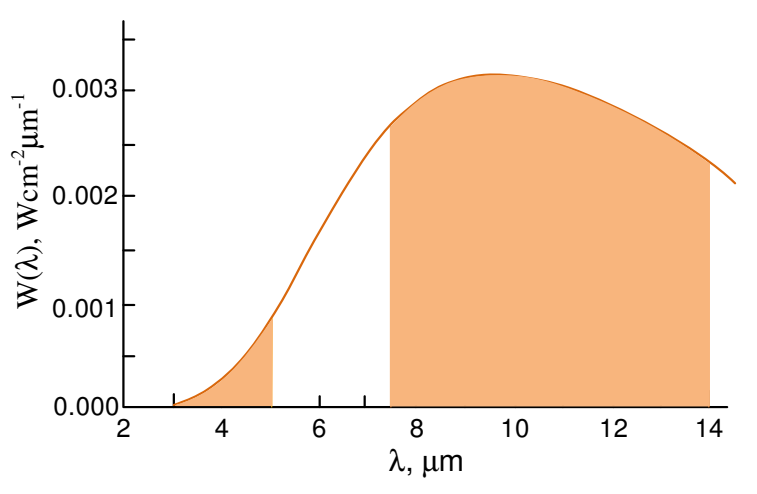

Fig. 2. Black-body spectral radiant exitance at $T=300 \mathrm{~K}$. The colored regions demonstrate the portions of the total power available for MWIR $(3 \ldots 5 \mu \mathrm{m})$ and LWIR $(7.5 \ldots 14 \mu \mathrm{m})$ ranges, respectively.

invasive and a painless tool for physiological functions related to skin-temperature control [81].

The heat transfer by radiation is of great importance in medicine, as the radiation flow from the body with temperature around $T \sim 310 \mathrm{~K}\left(T \sim 37{ }^{\circ} \mathrm{C}\right)$ is large. At this temperature, there is situated the maximum radiation power (see Fig. 2), and the amount of radiation power in the atmospheric window from $\sim 7.5$ to $14 \mu \mathrm{m}$, in which mainly the thermovision cameras operated, is appreciable. That is why the thermovision is an important instrument to control the thermal balance of human body. The nude human body emits in all spectral range from $\lambda=0$ to $\lambda=\infty$, according to the Stefan-Boltzmann law $W(T)=\sigma_{\mathrm{B}} \cdot T^{4}$, about $1 \mathrm{~kW}$ into environment. Here, $\sigma_{\mathrm{B}}=$ $=5.6686 \cdot 10^{-12} \mathrm{~W} /\left(\mathrm{cm}^{2} \cdot \mathrm{K}^{4}\right)$ is the Stefan-Boltzmann constant, and it is assumed that the surface area of human body is $S \approx 2 \mathrm{~m}^{2}$.

At the same temperature of an environment, the human body is in equilibrium with it and, therefore, does not loose energy. Whereas, e.g., at an environment temperature lower $\Delta T \approx 20 \mathrm{~K}$ the human body heat losses are about $250 \mathrm{~W}$ and an undressed person will quickly chill.

The IR technologies are finding extensive applications in technical vision systems, since the temperature of the objects heated to mean Earth surface temperature for the max emission is around $300 \mathrm{~K}$. Within the transmission windows $3 \ldots 5$ and $8 \ldots 14 \mu \mathrm{m}$, it allows using such instrumentation as thermal passive imagers for remote sensing and vision at large-scale distances at night or day surveillance, when different kinds of camouflages are used for objects to be hidden in the visible spectral region.

The development of IR detectors in $19^{\text {th }}$ and at the beginning of $20^{\text {th }}$ centuries was basically related with the thermal uncooled detectors, which response on "heat" changing their properties under radiation within the whole spectral range. These were thermocouples and bolometers. In 1830, L. Nobili proposed the thermocouple as an IR detector [82]. In the 1833, the multielement thermopile was applied by M. Melloni to show that a person $10 \mathrm{~m}$ away could be detected by focusing his or her thermal energy on that device [8]. In 1880, S.P. Langley [83], whose main interest was in the use of the detectors in astronomy, proposed a bolometer as thermal detector and stated that his bolometer could detect a cow moving across the field at 1/4 mile away.

In 1893, H. Rubens and B.W. Snow [84] presented an investigation on the refraction of rays in the materials pointed out. In 1896, E.F. Nichols [85] found that the reflectivity of crystalline quartz rose over a narrow wavelength range near $9 \mu \mathrm{m}$ from a few $\%$ up to almost the reflectivity of a metal. The reflected radiation from crystalline quartz is due to lattice vibrations and was detected with the new radiometer. The spectral range of high reflectivity in ionic crystals (the range between the longitudinal and transverse optical phonon frequencies) now is attributed to the restrahlen band.

H. Rubens and E.F. Nichols built a spectrometer using multiple restrahlen plates to isolate a very narrow wavelength band. By changing the reflecting plates, they could then produce nearly the monochromatic radiation at a number of different wavelengths, out to beyond $50 \mu \mathrm{m}[12]$.

At the end of 1890 s, the radiation from hot bodies and its wavelength dependence were of important concern. Unfortunately, the experimental data obtained and compared with the blackbody used as an ideal source, did not agree with the theory. In the 1900, H. Rubens and K. Kurlbaum (see, e.g., [86]), using the restrahlen spectrometer, obtained the required experimenal data in IR range. H. Rubens immediately visited Max Planck to give him the results who that same day wrote down the equation. These results were published in [87], which is now called Planck's Radiation Law.

In 1909, A. Einstein, analyzing the energy and momentum fluctuations in the blackbody radiation, assumed the validity of Planck's law and showed that the expressions for the mean-square energy and momentum fluctuations split into a sum of two terms. The first is a wave term that dominates in the Rayleigh-Jeans (long wavelengths) range of the spectrum and the second a particle term that dominates in the Wien law (short wavelengths) spectral range [88]; cited in Ref. [89]. Both terms were necessary to describe the fluctuations for the complete blackbody spectrum.

In 1911, H. Rubens and coworkers showed that the mercury arc lamp in a quartz envelope was a longwavelength IR source able to emit very long wavelength radiation (210 and $324 \mu \mathrm{m}, \mathrm{THz}$ range) [90, 91]. This source is still that one capable to generate radiation at those frequencies (in the $30 . .50 \mathrm{THz}$ range).

In 1913, one of the first examples for security applications probably was presented. It was L. Bellingham, who patented "an IR eye" capable to detect "icebergs" at a distance [8].

The second kind of detectors, apart of the thermal detectors that is called now the photon detectors, was mainly developed during the $20^{\text {th }}$ century although the photoconductivity effect (observable in photon detector) 
was discovered in 1873 (W. Smith), in experiments with selenium as an insulator. In 1917, T.W. Case developed photoconductive detectors based on $\mathrm{Tl}_{2} \mathrm{~S}$. In 1904, verily a photovoltaic detector in galena (natural $\mathrm{PbS}$ ) - solidstate diode detector to detect EM waves - was patented by J. Bose [21] (see part "History of THz technologies").

The period between the World Wars I and II can be characterized by the development of photon detectors and image converters. This idea of an image tube was proposed in 1928 [92]. In 1934, there was created [93] the first successful IR converter tube (Holst' cup). This tube consisted of a photocathode in close proximity to a fluorescent screen. Electrons knocked out from the photocathode by IR photons strike the fluorescent screen thus transferring an IR image into the visible region. These image tubes (now called intensifiers with photocathode, micro-channel plates and fluorescent screen as the basic elements) are sensitive in the short range $(\lambda \sim 0.8 \ldots 1.1 \mu \mathrm{m})$ of the IR spectra.

In 1928, M. Czerny documented the first infrared image of a human subject [94]. The infrared thermal imaging, applied for recording the surface temperatures of the human body in early trials in medicine started in 1952 in Germany [95]. A single IR bolometer for thermal measurement of defined regions of the human body surface for diagnostic purposes was developed [96]. In 1954 , the first medical association of thermography was established in Germany.

From that time, the medical IR imaging covers a broad field of applications. Among these applications female breast cancer, neurology, vascular imaging, forensic, surgery, etc., and now is an efficient means of a noncontact radiometric technique [97, 98].

In the 1930-1940s, there were considerable needs to register the radiant emission from the objects. In 1934, J. Hardy showed that the human skin surface has the characteristics of a near perfect black body radiator, being highly efficient in irradiative heat exchange [99, 100]. He pointed out, that it is important to know the precise value of emissivity because an emissivity difference of 0.945 to 0.98 may cause an error of skin temperature of $0.6^{\circ} \mathrm{C}$. J. Hardy showed that the human skin, regardless of color, is a highly efficient radiator with an emissivity of 0.98 , which is close to that of a black body. In 1960, K. Lloyd-Williams et al. showed that many tumors are hotter than adjacent skin parts [101]. Therefore, it was hoped that the thermosense technique can be used for screening the breast cancer.

In 1933, E.W. Kutzscher (Germany) discovered that lead sulphide $(\mathrm{PbS})$ is photoconductive to about $3 \mu \mathrm{m}$ wavelength. These detectors were the first practical infrared detectors that have found a variety of applications during the World War II. After this war, R.J. Cashman in the USA found that other lead salts (PbSe and $\mathrm{PbTe}$ ) can be used as infrared detectors [102].

During and after the World War II, the IR detector technology development was primarily driven by military applications [79, 80]. In the former USSR, there were developed systems for the army and navy. The progress was gained in night vision devices mainly for military applications (IR vidicons and other electro-optical converters).

The first cooled bolometer was invented in the 1940s [103]. The bolometer was cooled at superconducting region using liquid helium. It was used the superconducting transition point of tantalum at $4.4 \mathrm{~K}$. A later version was made with niobium nitride, which has a transition at about $15 \mathrm{~K}$ and proper operation of the bolometer at $14.3 \mathrm{~K}$ was achieved, where the cooling system with liquid hydrogen was more easily available [104].

The significant post-World War II event was the invention of room temperature pneumatic detectors. In 1946, Zahl and Golay published the paper on "Pneumatic heat detector" [105] referred more to $\mathrm{THz}$ range. One year later, Golay individually published the paper [106] and patented the pneumatic detector referred to as the Golay Cell. These inventions were the extension of works made by Zahl and Golay in the 1930s. In 1938, Zahl patented a "pneumatic cell detector". One year later, he and Golay patented a "System for detecting sources of radiant energy" [10].

In 1959, Lawson and co-workers [107] proposed the narrow band-gap mercury-cadmium-telluride (MCT) $\left(\mathrm{Hg}_{1-\mathrm{x}} \mathrm{Cd}_{\mathrm{x}} \mathrm{Te}\right)$ solid solution as the material with variable band-gap to be applied for IR detectors with the sensitivity wavelength changeable by chemical composition " $x$ ". This opened a new era in IR detector technology (a little bit later in 1960 A.D. Sneider and I.V. Gavrishak in Ukraine also grew $\mathrm{Hg}_{1-\mathrm{x}} \mathrm{Cd}_{\mathrm{x}}$ Te for IR detectors [108]. The development of this material inaugurated a revolutionary step of cooled IR detectors broad development and presumably the nearest decade, different vision systems with large focal plane arrays with ultimate performance for IR spectra from $\sim 1 \mu \mathrm{m}$ to $\sim 20 \mu \mathrm{m}$ will be based on $\mathrm{HgCdTe}$ semiconductor for both the Earth and Space location.

In the 1970s, development of a multi-element photon detector linear array started, which formed the basis of a real-time imaging process. Somewhat later, computer technology made a widespread impact on improvements in thermal imaging cameras, both on image quality and speed of image frame rate. Still, early imaging systems were large with very limited facilities for display and temperature measurement [109]. The computer image processing of thermograms resulted in increased possibilities for quantitation and archiving of images. Therefore, it increased the needs for the standardization of the IR biomedical imaging [110, 111].

The other type of photon detector appeared after publication in 1985 the paper [112]. In this research, they first observed the intersubband optical transitions in quantum wells (QWs). By 1987, the basic operating principles for QW infrared photodetectors (now frequently cold QWIPs) demonstrating sensitive infrared detection were formulated. The QWIP arrays were first used in Landsat Data Continuity Mission (2013) in IR bands 10.8 and $12.0 \mu \mathrm{m}$ [113]. 
Photon detectors were dominating in IR technologies up to the end of $20^{\text {th }}$ century. The essential drawback of photon detectors with ultimate performance is the need of cryogenic cooling. This is necessary to prevent the charge carrier thermal generation thus raising the noise level.

The second revolution in thermal imaging began in the recent decades of the $20^{\text {th }}$ century after using the results of investigations of small area and mass of uncooled thermal detectors for military and civilian applications. In 1978, Texas Instruments (USA) patented uncooled ferroelectric infrared detectors using barium strontium titanate $\left(\mathrm{BST}-\mathrm{BaSrTiO}_{3}\right)$. A little bit later, in the 1982, another uncooled detector technology (resistive microbolometer technology) was developed in Honeywell (USA) under the direction of R. Andrew (see [114]). Later it appeared after realization that the key to bolometer performance was not the resistive material but the structure's thermal isolation. The chosen by Honeywell material was vanadium oxide $\left(\mathrm{VO}_{\mathrm{x}}\right)$ which has a high $\left(\sim 2 \ldots 4 \% \mathrm{~K}^{-1}\right)$ temperature coefficient of resistance at room temperature and which was produced using silicon technology. It was deposited on a microbridge of $\mathrm{Si}_{3} \mathrm{~N}_{4}$. In the mid of 1990s (SOFRADIR + ULIS, France), a third technology, amorphous silicon $(\alpha-$ $\mathrm{Si}$ ), was also developed as compatible with fabrication in a silicon foundry [102].

Now these detector and thermal camera technologies are well mastered by several companies: Raytheon, Teledyne, BAE Systems, DRS Technologies, FLIR, L-3 Communications, Goodrich Corporation and some others (USA), NEC, Mitsubishi (Japan), XenICs (Belgium), SCD (Israel), INO (Canada) and so on.

Beginning from the late $1970 \mathrm{~s}$, progress in the number of detectors in arrays, which revolutionized IR technologies and made them much more cost-effective, was primarily related with application of silicon readout integrated circuits (ROICs). Assembling ROICs with different types of detectors allowed building up the IR focal plane arrays (FPAs), which now can contain in single crystal array up to $\sim 10^{7}$ and more IR detectors. Applications of these technologies made it possible to discretize the process of image creation as well as its processing by the instrumentality of linear and matrix detector arrays from discrete elements. The arrays, both IR and $\mathrm{THz}$, used in vision systems have a set of advantages over the systems with single detectors. It is related, first of all, with the rate of getting image (and also information capacity), space resolution, sensitivity and visibility range.

The IR thermography (passive vision) is one of the useful techniques that are used in non-destructive testing of human body. Using infrared technology has many advantages such as the fact that it is a contactless method, non-destructive and fast technique, which does not emit any harmful radiations [115]. Now the IR thermography strives towards using equipment offering high performance, acceptable accuracy and low cost $[116,117]$.
In most cases imaging the objects or environment that is related with detecting the IR or THz signals in the spectral regions from their "invisible" parts can be substantially different from images in the visible part of spectra. This is caused by different radiation absorption, transmission and reflection of the objects under observation, their emissivity, background temperature, etc., in various spectral ranges.

The history of IR technologies itself and in application to various types of activity in different periods is presented in a number of papers and books, too (see, e.g., [118-125]).

\section{Summary}

The brief history of $\mathrm{THz}$ and IR science and technology, for learning lessons by historical evolution is presented and discussed identifying important (from the author's point of view) steps for their development. THz science and technology, with account of the fact they are showing a rapid growth, nowadays become widely spread in their use despite the explosion of application requirements especially in astrophysics, security, biomedicine, etc. Still, THz science and technology need a deeper and wider knowledge in many scientific and technological aspects. Besides, in spite of expected progress, the $\mathrm{THz}$ technologies are still delayed in a widespread use because of a lack of reliable, cost effective sensors, sources and instrumentations produced on a large scale.

The situation is less concerned the IR technologies, especially in the thermovision. A few decades ago, the IR technologies were mainly the domain of military ones. In recent two decades, due to widespread of thermal uncooled detectors there were realized many IR technology advances. Quick falling down costs of the IR arrays and instrumentations are observed. Uncooled thermal IR arrays have become an alternative to the cooled ones and now are much more commonly applied in many commercial, industrial, biomedical and military IR applications.

Over the several recent decades, the IR detectors successful development for large format small pixel arrays and cameras on their base, lead to a significant progress in monitoring of environmental pollution, surveillance and reconnaissance, security imaging, IR astronomy, car driving, imaging in medical diagnostics, etc.

Although no real $\mathrm{THz}$ technologies mass-market applications can be highlighted, because of these technologies does not meet yet the users requirements especially in easiness of use and costs, many of $\mathrm{THz}$ applications have now are emerging and showing an applicability in astrophysics, security, biomedicine, drug and dry food inspection, nondestructive testing, etc. Still, summarizing the development of $\mathrm{THz}$ technologies, one can conclude that in spite of the great efforts in the past decades, $\mathrm{THz}$ applications in general are still at an early stage of development. Many other potential applications are likely to be added in future. 


\section{References}

1. Hochrein T. Markets, availability, notice, and technical performance of terahertz systems: Historic development, present, and trends. J. Infrared, Millimeter, and Terahertz Waves. 2015. 36. P. 235254.

2. Dhillon S.S. et al. (32 Coauthors). The 2017 terahertz science and technology roadmap. J. Phys. D: Appl. Phys. 2017. 50. P. 043001.

3. Walther M., Fischer B.M., Ortner A., Bitzer A. et al. Chemical sensing and imaging with pulsed terahertz radiation. Anal. Bioanal. Chem. 397 (2010) 1009-1017].

4. Emerson D.T. The work of Jagadis Chandra Bose: 100 years of millimeter-wave research. IEEE Trans. Microwave Theory Techn. 1997. 45. P. 2267-2273.

5. Aggarwal V. Jagadish Chandra Bose: The real inventor of Marconi's wireless detector; http://web.mit.edu/varun_ag/www/bose_2006.pdf.

6. US Patent 676,332. Apparatus for wireless telegraphy, G. Marconi. Patented June 11, 1901. Application Feb. 23, 1901.

7. Bondyopadhyay P.K. Sir J.C. Bose's diode detector received Marconi's first transatlantic wireless signal of December 1901 (The "Italian Navy coherer" scandal revisited). Proc. IEEE. 1998. 86. P. 259285.

8. Corsi C. TeraHertz: Quasioptics or sub-millimeter waves? History, actual limits and future developments for security systems, in: C. Corsi, F. Sizov (Eds.), $\mathrm{THz}$ and Security Applications. Dordrecht: Springer, 2014. P. 1-24.

9. THz Pioneers. IEEE Trans. THz Sci. Technol. 2012. 2. P. 265-270; 2012. 2. P. 477-484; 2014. 4. P. 137-146; 2014. 4. P. 645-652.

10. Bründermann E., Hübers H.-W., Kimmitt M.F. Terahertz Techniques. Heidelberg: Springer, 2011.

11. Gordy W. Early events and some later developments in microwave spectroscopy. J. Mol. Struct. 1983. 97. P. 17-32.

12. Kimmitt M.F. Restrahlen to T-rays: 100 years of terahertz radiation. J. Biolog. Phys. 2003. 29. P. 7785.

13. Chamberlain J.M. Where optics meets electronics: recent progress in decreasing the terahertz gap, Phil. Trans, R. Soc. Lond. A. 2004. 362. P. 199-213.

14. Blaney T.G. Signal-to-noise ratio and other characteristics of heterodyne radiation receivers. Space Sci. Rev. 1975. 17. P. 691-702.

15. Richards P. Bolometers for infrared and millimeter waves. J. Appl. Phys. 1994. 76. P. 1-24.

16. Chattopadhyay G. Sensor technology at submillimeter wavelength for Space applications. Int. J. Smart Sens. Intell. Systems. 2008. 1. P. 1-20.

17. Lamarre J.M., Desert F.X., Kirchner T. Background limited infrared and sub-millimeter instruments. Space Sci. Rev. 1995. 74. P. 27-36.

18. Kangro H. Early History of Planck's Radiation Law. New York: Taylor \& Francis, 1976.
19. P Siegel. THz pioneer: Richard S. Saykally Water, water everywhere... IEEE Trans. Terahertz Sci. Technol. 2012. 2. P. 265-270.

20. Bose Jagadis Chandra. On a self-recovering coherer and the study of the cohering action of different metals. Proc. IEEE. 1998. 86. P. 244-247 (reprinted from: Bose J.C. On a self-recovering coherer and the study of the cohering action of different metals. Proc. Royal Soc., London. 1899. LXV no. 416. P. 166-172.

21. U.S. Patent 755,840. Detector for electrical disturbances, J.C. Bose, filed September 30, 1901 (1904).

22. Pearson G.L. and Brattain W.H. History of semiconductor research. Proc. IRE. 1955. 43. P. 1794-1806.

23. Glagolewa-Arkadiewa A. Short electromagnetic waves of wave-length up to 82 microns. Nature. 1924. 113. P. 640.

24. Kostenko A.A., Nosich A.I., Tishchenko I.A. Development of the first Soviet 3-coordinate Lband pulsed radar in Kharkov before WW II. IEEE Antennas Propagat. Mag. 2001. 44. P. 28-49.

25. Nosich A.I. Dramatic history and impact of decimeter-wave radar "Zenit" developed in Kharkiv in the 1930s. XXII International Seminar/Workshop on Direct and Inverse Problems of Electromagnetic and Acoustic Wave Theory (DIPED), Dnipro, Ukraine, 25-28 Sept., 2017. P. 11-14.

26. Gordy W. Microwave spectroscopy. Rev. Modern Phys. 1948. 20. P. 668-689.

27. Burrus C.A., Jr., Gordy W. Submillimeter wave spectroscopy. Phys. Rev. 1954. 93. P. 897-898.

28. Alpher V.S. Ralph A. Alpher, George Antonovich Gamow, and the prediction of the cosmic microwave background radiation. Asian J. Phys. 2014. 23. P. 17-26.

29. Fixsen D.J. The temperature of the cosmic microwave background. Astrophys. J. 2009. 707. P. 916-920.

30. Lineweaver Ch.H. Cosmic microwave background, in: Discoveries in Modern Science: Exploration, Invention, Technology, J. Trefil (Ed.). Farmington Hills: Macmillan, 2014. P. 224-229.

31. Penzias A.A., Wilson R.W. A measurement of excess antenna temperature at $4080 \mathrm{Mc} / \mathrm{s}$. Astrophys. J. 1965. 142. P. 419-421.

32. Warnecke R., Guenard P. Some recent work in France on new types of valves for the highest radio frequencies. Proc. IEE -Radio Commun. Eng. 1953. 100, no. 68, pt. III. P. 351-362.

33. Read W.T. A proposed high frequency negative resistance diode. Bell. Syst. Tech. J. 1958. 37. P. 401-446.

34. Tager A.S. The avalanche-transit diode and its use in microwaves. Sov. Phys. Usp. 1967. 9. P. 892912.

35. Jonston R.L., De Loach B.C., Cohen B.G. A silicon diode microwave oscillator. Bell Syst. Techn. J. Briefs. 1965. 44. P. 369. 
36. Brand F.A., Higgins V.I., Baranowski L.I., Druesne M.A. Microwave generation from avalanching varactor diodes. Proc. IEEE. 1965. 53. P. 12761277.

37. Gunn J.B. Microwave oscillation of current in III-V semiconductors. Solid State Commun. 1963. 1. P. 88-91.

38. Crocker A., Gebbie H.A., Kimmitt M.F., Mathias L.E.S. Stimulated emission in the far infra-red. Nature. 1964. 201. P. 250-251.

39. Chang T.Y., Bridges T.J. Laser action at 452, 496, and $541 \mu \mathrm{m}$ in optically pumped $\mathrm{CH}_{3} \mathrm{~F}$. Opt. Commun. 1970. 1. P. 423-426.

40. Richards P.L. High-resolution Fourier transform spectroscopy in the far-infrared. J. Opt. Soc. Am. 1964. 54. P. 1474-1484.

41. Webb S.J., Dodds D.D. Inhibition of bacterial cell growth by 136 gc microwaves, Nature. 1968. 218. P. 374-375.

42. Blackman C.F., Benane S.G., Weil C.M., Ali J.S. Effects of non-ionizing electromagnetic radiation on single-cell biologic systems. Annals of the New York Acad. Sci. 1975. 247. P. 352-366.

43. Nicolson A.M. Broad-band microwave transmission characteristics from a single measurement of the transient response. IEEE Transactions on Instrumentation and Measurement. 1968. 17, No 4. P. 395-402.

44. Schottky W., Stormer R., Waibel F. Uber die Gleichrichterwirkungenan der Grenze von Kupferoxydul gegen aufgebrachte Metallelektroden (On the rectifying action of cuprous oxide in contact with other metals). Z. Hochfrequenz. 1931. 37. P. 162-167, 175-187.

45. Kreisler A.J.M. Submillimeter wave applications of submicron Schottky diodes. Proc. SPIE. 1966. 666. P. 51-63.

46. Richards P.L., Shen T.M., Harris R.E., Lloyd F.L. Quasiparticle heterodyne mixing in SIS tunnel junctions. Appl. Phys. Lett. 1979. 34. P. 345-347.

47. Faries W., Gehring K.A., Richards P.L., Shen Y.R. Tunable far-infrared radiation generated from difference frequency between two ruby lasers. Phys. Rev. 1969. 180. P. 363-365.

48. Yajima T., Takeuchi N. Far-infrared difference frequency generation by picosecond laser pulses. Jap. J. Appl. Phys.1970. 9. P. 1361-1371.

49. Kazarinov R.F., Suris R.A. Possibility of amplification of electromagnetic waves in a semiconductor with a superlattice. Fizika i Tekhnika Poluprovodnikov. 1971. 5. P. 797-800 (in Russian).

50. Faist J., Capasso F., Sivco D., Cirtori C. et al. Quantum cascade laser. Science. 1994. 264. P. 553556.

51. Barker D.H., Hodges D.T., Hartwick T.S. Far infrared imagery. Proc. SPIE. 1975. 67. P. 27-34.

52. Auston D.H. Picosecond optoelectronic switching and gating in silicon. Appl. Phys. Lett. 1975. 26. P. $101-103$.
53. Auston D.H., Smith P.R. Generation and detection of millimeter waves by picosecond photoconductivity. Appl. Phys. Lett. 1983. 43. P. 631-633.

54. Kazanskii A.G., Richards P.L., Haller E.E. Far infrared photoconductivity of uniaxially stressed germanium. Appl. Phys. Lett. 1977. 31. P. 496-497.

55. Tuengler P., Keilmann F., Genzel L. Search for millimeter microwave effects on enzyme or protein functions. Zeitschrift fur Naturforschung C. 1979. 34. P. 60-63.

56. Hintzsce H., Stopper H. Effects of terahertz radiation on biological systems. Critical Rev. Environmental Sci. Technol. 2012. 42. P. 24082434.

57. Mourou G., Stancampiano C.V., Antonetti A., Orszag A. Picosecond microwave pulses generated with a subpicosecond laser-driven semiconductor switch. Appl. Phys. Lett. 1981. 39. P. 295-296.

58. Auston D.H., Cheung K.P., Smith P.R. Picosecond photoconducting Hertzian dipoles, Appl. Phys. Lett. 1984. 45. P. 284-286.

59. Fattinger C., Grischkowsky D. Terahertz beams. Appl. Phys. Lett. 1989. 54. P. 490-492.

60. Smith P.R., Auston D.H., Nuss M.C. Subpicosecond photoconducting dipole antenna. IEEE J. Quantum Electron. 1988. 24. P. 255-260.

61. Spence D.E., Kean P.N., Sibbett W. Sub-100 fs pulse generation from a self-mode-locked titanium: sapphire laser. Conference on Lasers and Electrooptics, CLEO, Technical Digest Series: Opt. Soc. of America, 1990. P. 619-620.

62. Auston D.H., Nuss M.C. Electrooptic generation and detection of femtosecond electrical transients. IEEE J. Quant.Electr. 1988. 24. P. 184-197.

63. Elias L.R., Hu J., Ramian G. The UCSB electrostatic accelerator free electron laser: First operation. Nucl. Instrum. Meth. Phys. Res. A. 1984. 237. P. 203-206.

64. Gershenzon E.M., Gershenson M.E., Goltsman G.N., Semenov A.D., Sergeev A.V. On the limiting characteristics of high-speed superconducting bolometers. Sov. Phys. Tech. Phys. 1989. 34. P. 195-201 (in Russian).

65. Sizov F. THz radiation detectors: the state of the art. Semicond. Sci. Techn. 2018. 33. P. 123001.

66. Putley E.H. Indium antimonide submillimeter photoconductive detectors. Appl. Opt. 1965. 4. P. 649-657.

67. Arams F., Allen C., Peyton B., Sard E. Millimeter mixing and detection in bulk InSb, Proc. IEEE. 1966. 54. P. 612-622.

68. Brown E.R., McIntosh K.A., Smith F.W., Manfra M.J., Dennis C.L. Measurements of opticalheterodyne conversion in low-temperature-grown GaAs. Appl. Phys. Lett. 1993. 62. P. 1206-1208.

69. Zhang X.-C., Xu J. Introduction to $\mathrm{THz}$ Wave Photonics. New York-Dordrecht-HeidelbergLondon: Springer, 2010. 
70. Adam A.J.L. Review of near-field terahertz measurement methods and their applications. $J$. Infrared, Millimeter, and Terahertz Waves. 2011. 32. P. 976-1019.

71. Dyakonov M., Shur M.S. Plasma wave electronics: Novel terahertz devices using two dimensional electron fluid. IEEE Trans. Electr. Devices. 1996. 43. P. 1640-1645.

72. Lü J.-Q., Shur M.S., Hesler J.L., Sun L., Weikle R. Terahertz detector utilizing two-dimensional electronic fluid. IEEE Electr. Device Lett. 1998. 19. P. 373-375.

73. Vicarelli L., Vitiello M.S., Coquillat D., Lombardo A. et al. Graphene field-effect transistors as roomtemperature terahertz detectors. Nature Mater. 2012. 11. P. 865-871.

74. Simoens F., Martyrs J. Terahertz real-time imaging uncooled array based on antenna - and cavitycoupled bolometers. Philosoph. Trans. R. Soc. A. 2014. 372. P. 20130111.

75. Nagatsuma T., Ducournau G., Renaud C.C. Advances in terahertz communications accelerated by photonics. Nature Photonics. 2016. 10. P. 371379.

76. Duan G.-H., Jany Ch., Le Liepvre A., Accard A. et al. Hybrid III-V on silicon lasers for photonic integrated circuits on silicon. IEEE J. Select. Topics Quant. Electron. 2014. 20. P. 6100213.

77. Doerr C.R. Silicon photonic integration in telecommunications. Front. Phys. 2015. 3. P. 1-16.

78. Lequeux J. Early infrared astronomy. J. Astron. History Heritage. 2009. 12. P. 125-140.

79. Ring F.J. Pioneering progress in infrared imaging in medicine. Quantitative InfraRed Thermography $J$. 2014. 11. P. 57-65.

80. Ring F.J., Jones B.F. Historical development of thermometry and thermal imaging in medicine, in: M. Diakides, J. D. Bronzino, and D. R. Peterson (Eds.), Medical Infrared Imaging: Principles and Practices. CRC Press, Boca Raton, 2013. P. 2.1-2.6.

81. Jiang L.J., Ng E.Y., Yeo A.C. et al. A perspective on medical infrared imaging. J. Med. Eng. Technol. 2005. 29. P. 257-267.

82. Barr E.S. Historical survey of the early development of the infrared spectral region. Amer. J. Phys. 1960. 28. P. 42-54.

83. Langley S.P. The bolometer. Nature. 1881. 25. P. 14-16.

84. Rubens H., Snow B.W. On the refraction of rays of great wavelength in rock salt, sylvine, and fluorite. Phil. Mag. 1893. 35. P. 35-45.

85. Nichols E.F. A method for energy measurements in the infrared spectrum and the properties of the ordinary ray in quartz for waves of great wavelength. Phys. Rev. 1897. 4. P. 297-313.

86. Rubens H., Kurlbaum F. Anwendung der Methode der Restrahlen zur Prufung des Strahlungsgesetzes. Annalen der Physik. 1901. 4. P. 649-666.
87. Planck M. Über eine Verbesserung der Wienschen Spektralgleichung. Verhandlungen der Deutschen Physikalischen Gesselschaft. 1900. 2. P. 202-204.

88. Einstein A. Zum gegenwärtigen Stand des Strahlungsproblems. Physikalische Zeitschrift. 1909. 10. P. 185-193.

89. Stuewer R.H. Einstein's revolutionary lightquantum hypothesis. Acta Phys. Polon. B. 2006. 37. P. 543-558.

90. Rubens H., Baeyer O.V. On extremely long waves emitted by the quartz mercury lamp. Phil. Mag. 1911. 21. P. 689-703.

91. Rubens H., Wood R.W. Focal isolation of long heat-waves. Phil. Mag. 1911. 21. P. 249-261.

92. Holst G., de Boer J.H., Teves M.C., Veenemans C.F. Foto-electrische cel en inrichting waarmede uit een primair, door directe lichtstralen gevormd beeld een geheel ofnagenoed geheel conform secundair optisch beeld kan. Dutch patent 27062 (1928); British Patent 326200; D.R.P. 535208.

93. Holst G., de Boer J.H., Teves M.C., Veenemans C.F. An apparatus for the transformation of light of long wavelength into light of short wavelength. Physika. 1934. 1. P. 297-305.

94. Czerny M. Über Photographie im Ultraroten. Zeitschrift für Physik. 1929. 3, Issue 1-2. P. 1-12.

95. Berz R., Sauer H. The medical use of infraredthermography. History and recent applications, Thermografie-Kolloquium 2007, Vortrag 04, 1-12, 2007 (www.ndt.net/search/docs.php3?MainSource=61).

96. Schwamm E., Reeh J. Die Ultrarotstrahlung des Menschen und seine Molekular spektroskopie. Hippokrates. 1953. 24. P. 737-742.

97. Ring F.J., Ng E.Y.K. Infrared thermal imaging standards for human fever detection, in: $\mathrm{M}$. Diakides, J.D. Bronzino, D.R. Peterson (Eds.), Medical Infrared Imaging: Principles and Practices. CRC Press, Boca Raton, 2013. P. 22.1-22.5.

98. Fernandez-Cuevas I., Marins J.C.B., Lastras J.A. et al., Classification of factors influencing the use of infrared thermography in humans: A review. Infrared. Phys. Technol. 2015. 71. P. 28-55.

99. Hardy J.D. The radiation of heat from the human body. J. Clinical Invest. 1934. 13. P. 615-620.

100. Hardy J. The radiation power of human skin in the infrared. Am. J. Physiol. 1939. 127. P. 454-462.

101. Lloyd-Williams K., Lloyd-Williams F., Handley R. Infrared radiation thermometry in clinical practice. Lancet. 1960. 2. P. 958-959.

102. Rogalski A. History of infrared detectors. OptoElectr. Rev. 2012. 20. P. 279-308.

103. Andrews D.H., Bruksch W.F., Zeigler W.T., Blanchard E.R. Attenuated superconductors for measuring infra-red radiation. Rev. Sci. Instrum. 1942. 13. P. 281-291.

104. Andrews D.H., Milton R.M., DeSorbo W. A fast superconducting bolometer. J. Opt. Soc. Am. 1946. 36. P. 518-524. 
105. Zahl H.A., Golay M.J.E. Pneumatic heat detector. Rev. Sci. Instrum. 1946. 17. P. 511-515.

106. Golay M.J.E. A pneumatic infra-red detector. Rev. Sci. Instrum. 1947. 18. P. 357-362.

107. Lawson W.D., Nielson S., Putley E.H., Young A.S. Preparation and properties of $\mathrm{HgTe}$ and mixed crystals of HgTe-CdTe. J. Phys. Chem. Sol. 1959. 9. P. 325-329.

108. Shneider A.D., Gavrishak I.V. Structure and properties of HgTe-CdTe system. Solid State Phys. 1960. 2. P. 2079-2081 (in Russian).

109. Ring E.F.J., and Ammer K. The technique of infrared imaging in medicine. Thermology Intern. 2000. 10. P. 7-14.

110. Ring E.F.J. Standardization of thermal imaging in medicine: Physical and environmental factors, in: M. Gautherie, E. Albert, L. Keith (Eds.), Thermal Assessment of Breast Health. MTP Press Ltd., Lancaster-Boston-The Hague, 1983. P. 29-36.

111. Ammer K. The Glamorgan Protocol for recording and evaluation of thermal images of the human body. Thermology Intern. 2008. 18. P. 125-129.

112. West L.C., Eglash S.J. First observation of an extremely large-dipole infrared transition within the conduction band of a GaAs quantum well. Appl. Phys. Lett. 1985. 46. P. 1156-1158.

113. https://www.nasa.gov/pdf/723395main_LDCMpres skit2013-final.pdf.

114. Kruse P.W. Uncooled Thermal Imaging. Arrays, Systems and Applications. SPIE Press, Bellingham, 2001.

115. Avdelidis N., Gan T.-H., Ibarra-Castanedo C., Maldague $\mathrm{X}$. Infrared thermography as a nondestructive tool for materials characterisation and assessment. Proc. SPIE. 2011. 8013. P. 8013OK.
116. Khodayar F., Sojasi S., and Maldague X. Infrared Thermography and NDT: 2050 Horizon. Quantitative InfraRed Thermography J. 2015. 13. P. 210-231.

117. Raghavendra U., Acharya U.R., Ng E.Y.K., Tan J.-H., Gudigar A. An integrated index for breast cancer identification using histogram of oriented gradient and kernel locality preserving projection features extracted from thermograms. Quantitative InfraRed Thermography J. 2016. 13. P. 195-209.

118. Smith R.A., Jones F.E., Chasmar R.P. The Detection and Measurement of Infrared Radiation. Oxford: Clarendon, 1958.

119. Hudson R.D. Infrared System Engineering. New Jersey: Wiley-Interscience, 1969.

120. Biberman L.M., Sendall R.L. Introduction: A brief history of imaging devices for night vision, in: L.M. Biberman (Ed.), Electro-Optical Imaging: System Performance and Modeling. SPIE Press, Bellingham, 2000. P. 1-1-1-26.

121. Sakai K. Terahertz Optoelectronics. Berlin: Springer, 2005.

122. Gilmore A.S. High-definition infrared FPAs. Raytheon Technology Today. 2008. Issue 1. P. 4-8.

123. Corsi C. History highlights and future trends of infrared sensors. J. Modern Opt. 2010. 57. P. 16631686.

124. Sclar N. Properties of doped silicon and germanium infrared detectors. Progr. Quant. Elect. 1984. 9. P. 149-257.

125. Vavilov V. Thermal NDT: historical milestones, state-of-the-art and trends. Quantitative InfraRed Thermography J. 2014. 11. P. 66-83. 